https://helda.helsinki.fi

\title{
Association between breastfeeding and better preserved cognitive ability in an elderly cohort of Finnish men
}

\section{Rantalainen, V.}

2018-04

Rantalainen , V , Lahti , J , Henriksson, M , Kajantie , E, Mikkonen , M , Eriksson , J G \& Räikkönen , K 2018 , ' Association between breastfeeding and better preserved cognitive ability in an elderly cohort of Finnish men ', Psychological Medicine, vol. 48 , no. 6 , pp. 939-951 . https://doi.org/10.1017/S0033291717002331

http://hdl.handle.net/10138/237154

https://doi.org/10.1017/S0033291717002331

acceptedVersion

Downloaded from Helda, University of Helsinki institutional repository.

This is an electronic reprint of the original article.

This reprint may differ from the original in pagination and typographic detail.

Please cite the original version. 


\section{Association between breastfeeding and better preserved cognitive ability in an elderly cohort of Finnish men}

\section{Authors and affiliations}

Ville Rantalainen, MA (Psych.) (ville.rantalainen@helsinki.fi). Department of Psychology and Logopedics, University of Helsinki, Finland; Folkhälsan Research Centre, Helsinki, Finland

Jari Lahti, PhD (jari.lahti@ helsinki.fi). Department of Psychology and Logopedics, University of Helsinki, Finland; Folkhälsan Research Centre, Helsinki, Finland

Markus Henriksson, MD, PhD (markus.henriksson@valvira.fi). National Supervisory Authority of Welfare and Health, Department of Health Care Supervision, Helsinki, Finland; Center of Military Medicine, Helsinki, Finland

Eero Kajantie, MD (eero.kajantie @thl.fi). Division of Welfare and Health Promotion, Department of Chronic Disease Prevention, Diabetes Prevention Unit, National Institute for Health and Welfare, Helsinki, Finland; Hospital for Children and Adolescents, Helsinki University Central Hospital and University of Helsinki, Helsinki, Finland; Department of Obstetrics and Gynaecology, Oulu University Hospital and University of Oulu, Oulu, Finland

Maiju Mikkonen, M.Soc.Sci (maiju.mikkonen@helsinki.fi). Department of Chronic Disease Prevention, National Institute for Health and Welfare, Helsinki, Finland; Faculty of Medicine, University of Helsinki, Finland

Johan G Eriksson, MD, DMSc (johan.eriksson@helsinki.fi). Department of General Practice and Primary Health Care, University of Helsinki and Helsinki University Hospital, Helsinki, Finland; Folkhälsan Research Center, Helsinki, Finland; Vasa Central Hospital, Vasa, Finland

Katri Raikkonen, PhD (katri.raikkonen@ helsinki.fi). Department of Psychology and Logopedics, University of Helsinki, Finland 


\section{ABSTRACT}

Background: Being breastfed in infancy has been shown to benefit neurodevelopment.

However, whether the benefits persist to old age remains unclear.

Methods: We examined the associations between breastfeeding and its duration on cognitive ability in young adulthood and old age, and on aging-related cognitive change over five decades. 931 men from the Helsinki Birth Cohort Study born in 1934-1944 in Finland took the Finnish Defence Forces Basic Intellectual Ability Test (total and verbal, arithmetic and visuospatial subtest scores) twice, at ages 20.2 and 67.9 years, and had data on breastfeeding (yes vs. no) and its duration ('never breastfed', 'up to 3', '3 to 6' and '6 or more months'). Linear and mixed model regressions tested the associations.

Results: At 20.2 years, breastfed men had higher cognitive ability total and visuospatial subtest scores (mean differences [MDs] ranged between 3.0-3.9, p-values<.013), and its longer duration predicted higher cognitive ability total and arithmetic and visuospatial subtest scores (MDs ranged between 3.0-4.8, p-values<.039). At 67.9 years, breastfed men had higher total cognitive ability and all subtest scores (MDs ranged between 2.6-3.4, p-values<.044) and its longer duration predicted all cognitive ability scores (MDs ranged between 3.1-4.7, pvalues<.050). Verbal subtest scores decreased over five decades in men who were never breastfed or were breastfed for three months or less, and increased in those breastfed for longer than three months.

Conclusions: Neurodevelopmental advantages of breastfeeding and its longer duration persist into old age, and longer duration of breastfeeding may benefit aging-related change, particularly in verbal reasoning ability. 


\section{INTRODUCTION}

Breastfeeding may benefit neurodevelopment by mechanisms related to nutritional content of breastmilk, namely long-chained polyunsaturated fatty acids that promote brain development, and to maternal sensitivity and mother-infant bonding (Horta \& Victora, 2013). Indeed, a cluster-randomised Probit trial showed that breastfeeding intervention was associated with cognitive advantage in childhood (Kramer et al. 2008), and a recent meta-analysis of 13 studies published up till 2011 suggested that being ever breastfed in infancy was associated with a 3.5 points higher intelligence quotient (IQ) in childhood and adolescence (Horta \& Victora, 2013). Not all studies have, however, confirmed these associations (e.g. Wigg et al, 1998), or have suggested that the associations are entirely accounted for by parental or socioeconomic factors (see review by Walfisch et al, 2013; Gibbs \& Forste, 2014). Yet, observational studies suggest that the cognitive benefits of breastfeeding may persist into adulthood. In these studies, where alternatives to and practices of breastfeeding have varied over time and place, longer duration of breastfeeding was associated with higher scores on intelligence tests in a Danish sample born between 1979-1981 and tested between 18.7 and 27.2 years (Mortensen et al, 2002), in a Brazilian sample born in 1982 and tested at 30-years of age (Victora et al. 2015), and in a British sample born in 1946 and tested at 53-years of age (Richards et al. 2002). One study in British adults born between 1920-1930 and tested at 70 years of age and above reported that being ever breastfed in infancy was not associated with intelligence in old age (Gale \& Martyn, 1996). Even though the discrepancy between the latter and the former studies may reflect the above-mentioned time and place -related differences in breastfeeding alternatives and practices, the latter study did not account for the duration of breastfeeding. Hence, it is not known if longer duration of breastfeeding is associated with benefits persisting to old age. It also remains unknown whether any benefits of breastfeeding predict aging-related cognitive change. 
We report here findings from a study that tested if ever being breastfed and longer duration of breastfeeding predicted better cognitive ability in old age and smaller aging-related cognitive change from young adulthood to old age in a sample of men. These data come from the Helsinki Birth Cohort Study (HBCS) which provides life-course epidemiological data on several important perinatal, maternal, sociodemographic and health-related covariates.

\section{METHODS}

\section{Participants}

The cohort, a subcohort of HBCS, comprises 4,630 men born between 1934 and 1944 in Helsinki, Finland who attended child welfare clinics and lived in Finland in 1971, when a personal identification number was allocated to all residents of the country. The cohort has been described in detail elsewhere (Barker et al. 2005; Eriksson et al. 2006). Breastfeeding data were available for everyone, and of them, cognitive ability data at military conscription at mean age 20.2 years $(\mathrm{SD}=1.4$, range $=17.0-28.1)$ were available for $2770 \mathrm{men}$; and at an invitation-based retest (those living within 200km radius from Helsinki were invited) (Raikkonen et al, 2013) in the year 2009 at age 67.9 years $(\mathrm{SD}=2.5$, range=64.5-75.7) for 931 men. These 931 men formed the analytic sample of this study. The mean time interval between the two cognitive tests was 47.7 years $(\mathrm{SD}=2.9$, range=38.9-54.7). Of the 2770 men with cognitive ability data available at 20.2 years but who did not participate in the cognitive ability retest, 640 had died, 204 had in a previous follow-up declined participation in any further follow-up, and 182 lived abroad.

The analytic sample differed from the rest of the cohort as follows: At birth, those in the analytic sample were more likely to have fathers in upper clerical occupations, and mothers in lower clerical occupations, they were taller at 6 months, and at 2 years they weighed more and were taller (all $p$-values<.04). Also, their lifespan maximum attained level of education was 
more often upper or lower tertiary, they were less likely to have been hospitalized for stroke (international classification of disease (ICD) codes 430-434 and 436-437 from ICD-8 and 9, 438 from ICD-9, and I60-I69 from ICD-10) or coronary heart disease (codes 410-414 from ICD-8 and ICD-9 and I21-I25 from ICD-10) ( $p$-values<.010), and at 20.2 years they scored higher on total cognitive ability and on verbal, arithmetic and visuospatial reasoning $(p<.001)$. There were no differences in breastfeeding status (never versus ever) or duration of breastfeeding between the analytic sample and the rest of the cohort ( $p$-values>.170). Characteristics of the rest of the cohort according to the history of breastfeeding are presented in Supplementary Table 1.

\section{Ethics statement}

The HBCS has been approved by the Ethics Committee of the National Public Health Institute and the Coordinating Ethics Committee of the Hospital District of Helsinki and Uusimaa. The Finnish Defence Command has given permission for data linkage (Permit number AL18521). All procedures contributing to this work comply with the Declaration of Helsinki. All participants have signed a written informed consent.

\section{Breastfeeding}

Data on being ever breastfed (no vs. yes) and breastfeeding duration (up to 3, 3 to 6 , or 6 or more months) were extracted from birth and child welfare clinic records (Kajantie et al. 2008).

\section{Cognitive ability}

The Finnish Defence Forces Basic Intellectual Ability Test consists of time-limited verbal, arithmetic, and visuospatial (analogous to Raven's progressive matrices (Raven 2000)) subtests and a total score. Each series consists of 40 multiple choice items with progressive difficulty. The test battery, with some modifications, has been in use since 1955. Its 
psychometric properties have been described in detail elsewhere (Raikkonen et al. 2009, Tiihonen et al. 2005), and differences in test scores have in previous studies been found to be associated with, for example, exposure to early-life stress (Pesonen et al. 2013), cardiovascular disease and stroke risk (Kajantie et al. 2012) and APOE gene polymorphisms (Rantalainen et al. 2016). At age 20.2 years the men were tested within the first two weeks of their compulsory military service. At age 67.9 years the men were re-tested using the same test battery as previously described (Raikkonen et al. 2013). For all analyses the cognitive ability test scores were square transformed to attain normality, and converted to usual intelligence-type scores with mean 100 and standard deviation 15.

\section{Covariates}

These included the following: weight $(\mathrm{g})$, length $(\mathrm{cm})$, ponderal index $\left(\mathrm{kg} / \mathrm{m}^{3}\right)$ and gestational age (from the date of the mother's last menstrual period) at birth, mother's age (years) at delivery and parity (primiparous vs. multiparous) extracted from hospital records; estimates of growth in weight, height and BMI between birth and 6, and between 6 and 24 months based on child welfare clinic records; mother's and father's occupational status in childhood (manual workers including farmers, junior clerical, senior clerical) extracted from hospital, child welfare or school health care records; highest own attained level of education in adulthood (basic/primary or less, upper secondary, lower tertiary, upper tertiary) and marital status (never married, married/widowed, divorced), recorded at five-year intervals between 1970-2000 derived from Statistics Finland; diagnoses of stroke (codes 430-434 and 436-437 from ICD-8 and 9, 438 from ICD-9, and I60-I69 from ICD-10) (Osmond et al. 2007), coronary heart disease (CHD) (codes 410-414 from ICD-8 and ICD-9 and I21-I25 from ICD10) (Barker et al. 2005) and any mental disorder (codes 291, 295, 296-305, 306.4-306.5, 306.8, 306.98 and 307 from ICD-8, 291-292, 295-298, 300-304, 305, 3071A, 3074, 3075A3075B, 3078A, 3079X, 3090A, 3092C-3099X and 312 from ICD-9 and F1-F6 from ICD-10) 
(Räikkönen et al, 2011) until the cognitive ability retest at age 67.9 years derived from the Finnish Hospital Discharge Register; and the participant's age at the cognitive ability testings.

\section{Statistical methods}

Linear regression analyses tested the associations of ever being breastfed (no vs yes) and breastfeeding duration (dummy coded for the analyses with 'never breastfed' as referent; the duration variable was also treated as continuous in tests for linear trend) and cognitive ability at age 20.2 and at 67.9 years. Mixed model regression analyses tested associations of breastfeeding with aging-related cognitive change. For these analyses cognitive ability at age 20.2 and 67.9 years represented the dependent outcome variable and ever being breastfed and breastfeeding duration (tested in separate models), time between the two cognitive testings and their interaction were the independent fixed effects.

We show the associations as unadjusted and adjusted for the covariates. Each analysis includes all participants with complete data for each statistical model. We first adjusted for age at testing and father's and mother's occupational status in childhood; and then made further adjustments for mother's age at delivery, parity, gestational age, birth weight and gain in weight to 6 and to 24 months of age. We also performed analyses using models replacing birth weight and gain in weight with birth length and gain in height and with birth ponderal index and gain in BMI but do not report these as the results did not substantially differ. In an additional model, we made adjustments for age at testing and own highest attained education in adulthood and marital status (67.9 years analyses only). Further, we re-ran the analyses at 67.9 years excluding those participants who had been diagnosed with stroke, coronary heart disease or any mental disorder $(n=166)$ prior to the cognitive ability retest. Because mother's and father's occupational status were highly related (Supplementary Table 2; note that of the 116 participants with missing data in mother's occupational status, which includes any 
mothers who were housewives, 115 had data on father's occupational status available), we tested the fit of the models and found good model fits. The variance in the cognitive ability total and subtest scores at age 20.2 and 67.9 years explained by a model which adjusted for father's occupational status only and a model which adjusted for both father's and mother's occupational status differed between $0.0 \%$ and $7.5 \%$. The correlations between observed cognitive ability scores and scores predicted by the model which adjusted for age at testing and mother's and father's occupational status ranged between 0.27 and 0.43 at 20.2 and 67.9 years (all p-values<.001).

\section{RESULTS}

Participant characteristics according to ever being breastfed are presented in Table 1. Of the covariates, only father's lower occupational status was associated with longer duration of breastfeeding $\left(\chi^{2}(9)=18.8, p=.027\right)$ (other $\mathrm{p}$-values $\left.\mathrm{p}>.095\right)$.

In this sample the intraclass correlations between the cognitive ability scores at the two testings were $0.77,0.65,0.74$, and $0.62,(p$-values $<.001)$ and average mean-level changes were $0.23(\mathrm{SD}=4.57$, range $=-22.67-18.00),-2.60(\mathrm{SD}=6.40$, range=-30.00-33.00), 2.19 $(\mathrm{SD}=4.90$, range $=-21.00-20.00)$ and $1.10(\mathrm{SD}=7.10$, range=-28.00-38.00 $)$ raw score points in the total score and in verbal, arithmetic, and visuospatial subtest scores, respectively.

\section{[TABLE 1]}

\section{Breastfeeding and cognitive ability at $\mathbf{2 0 . 2}$ years}

Table 2 shows that in unadjusted models being ever breastfed was associated with a higher visuospatial subtest score compared to those who were never breastfed (mean difference $[\mathrm{MD}]=3.29$ intelligence quotient $[\mathrm{IQ}]$ points, $95 \%$ confidence interval[CI]=0.73, 5.85). In models adjusting for the covariates, this association did not substantially change (MD's $>3.74$ IQ points, 95\% CI=1.42, 6.31), and being ever breastfed was also associated 
with a higher cognitive ability total score compared to those never breastfed (MD's $>3.00$ IQ points, $95 \% \mathrm{CI}=0.63,5.37)$. Being ever breastfed was not consistently associated with the arithmetic and verbal subtest scores in the unadjusted and adjusted models.

\section{[TABLE 2]}

Table 3 shows that total cognitive ability and visuospatial subtest scores were higher the longer the duration of breastfeeding. In models adjusting for covariates these associations did not substantially change, however the arithmetic subtest score was also higher the longer the duration of breastfeeding (Table 3). Longer duration of breastfeeding was not associated with the verbal subtest score in the unadjusted or adjusted models.

\section{[TABLE 3]}

\section{Breastfeeding and cognitive ability at 67.9 years}

Table 2 shows that in unadjusted models being ever breastfed was associated with higher cognitive ability total and verbal subtest scores compared to those who were never breastfed (MD's $>2.64$ IQ points, 95\% CI=0.07, 5.20). In models adjusting for covariates and when men with diagnoses of stroke, coronary heart disease or any mental disorder were excluded, these associations did not substantially change (MD's $>2.84$ IQ points, $95 \% \mathrm{CI}=0.32,5.37$ ). Arithmetic and visuospatial subtest showed a weak trend to be higher in breastfed men, but they were not consistently associated in unadjusted and adjusted models and when men with diagnoses of stroke or coronary heart disease or any mental disorder were excluded (Table 2).

Table 3 shows that in unadjusted models cognitive ability total and verbal, arithmetic and visuospatial subtest scores were higher the longer the duration of breastfeeding. In models adjusting for covariates and when men with diagnoses of stroke or coronary heart disease or any mental disorder were excluded, the associations did not substantially change (Table 3 ). 
Figure 1 depicts the cognitive ability total and subtest scores according to duration of breastfeeding, and Cohen's d effect sizes for the difference between those never breastfed and those breastfed for up to 3,3 to 6 , and 6 or more months.

\section{[FIGURE 1]}

\section{Breastfeeding and cognitive change between 20.2 and 67.9 years}

Being ever breastfed was not associated with change in cognitive ability total or subtest scores in unadjusted models or in models adjusting for covariates and when men with diagnoses of stroke, coronary heart disease or any mental disorder were excluded (data not shown).

Duration of breastfeeding was not associated with change in cognitive ability total, arithmetic or visuospatial subtest scores (data not shown). Yet, as shown in Figure 2, verbal subtest scores decreased over five decades in those never breastfed and in those breastfed for 0 to 3 months, while the scores increased in those breasted for 3 to 6 months or 6 months or more ( $\mathrm{MD}=0.02 \mathrm{IQ}$ points, $95 \% \mathrm{CI}=0.00,0.03$ ). In models adjusting for covariates and when men with diagnoses of stroke or coronary heart disease or any mental disorder were excluded, this association did not substantially change (MD's $>0.02$ IQ points, 95\% CI>0.00, 0.03). Cohen's

$\mathrm{d}$ effect sizes for the difference between those never breastfed and those breastfed for up to 3 , 3 to 6 , and 6 or more months are shown in Figure 2.

\section{[FIGURE 2]}

\section{DISCUSSION}

We report here that men who were breastfed had better cognitive ability in young adulthood than those who were never breastfed. This advantage was present in old age, especially in men who were breastfed for a longer duration. Our study also shows that longer duration of breastfeeding exerted an advantage for aging-related cognitive change: while verbal reasoning 
scores declined between 20.2 and 67.9 years in men who were never breastfed or breastfed for three months or less, they increased in men breastfed for three months or longer. The results were not explained by confounding related to maternal age or parity, maternal or paternal occupational status, prenatal conditions as indicated by birth weight and length of gestation, and early childhood conditions as indicated by physical growth up to 24 months. The associations also held when adjusted for the participant's highest lifetime attained education and marital status and when men with stroke, coronary heart disease or any mental disorder diagnoses were excluded from the analyses.

The associations between breastfeeding and its duration and cognitive ability at 20.2 and 67.9 years seemed to be domain-general. At 20.2 years the associations were strongest for visuospatial reasoning and weakest for verbal reasoning, whereas at 67.9 years there was little difference between the associations. At 20.2 years breastfed men scored between 1.5 and 3.7 and at 67.9 years between 2.4 and 3.4 IQ points higher, and those breastfed for longer between 0.6 and 4.8 IQ points higher at 20.2 years and between 0.8 and 4.7 IQ points higher at 67.9 years across the total score and all subtest scores. In effect size these differences are, however, small. We are aware of only one previous study of individuals born in the UK between 1920-1930 and whose IQ was tested in older age that reported against the study hypothesis that breastfeeding did not exert long-term neurodevelopmental benefits (Gale \& Martyn 1996); while the study lacked data on duration of breastfeeding, the discrepant finding may reflect that the alternatives to breastfeeding and consequent differences in quality of water supply and availability and affordability of means of sterilization may have differed as our study cohort was born up to 20 years later in Finland and the other cohorts were born more recently in the UK, Denmark and Brazil (Mortensen et al. 2002; Victora et al; 2015; Richards et al. 2002). Hence, our study shows that the neurodevelopmental advantages of breastfeeding and its longer duration seem to persist into old age in a cohort born between 
1930-1940. The advantages compared to those not breastfed were present in those breastfed for three months or longer. This suggests that the causal mechanism or mechanisms involved seem to function in an incremental manner and require longer exposure for significant advantages.

The other novel finding related to breastfeeding duration and aging-related change in verbal ability, that verbal ability decreased between early adulthood and old age, across nearly five decades, in those never breastfed or breastfed for shorter and increased in those breastfed for a longer duration, deserves further attention. It has been shown that different cognitive domains follow different aging trajectories. Effort-intensive abilities, sometimes called fluid intelligence, peak in young adulthood but decline with increasing age, whereas semantic memory processes, sometimes called crystallized intelligence, increase across the entire lifespan (Park et al. 2012). Breastfed infants also attain higher education (Victora et al. 2015), which can in part derive from their higher cognitive ability and has also been found in some (Habib et al. 2007), but not all (Van Dijk et al. 2008), studies to protect against aging-related cognitive change. Thus, it appears that breastfeeding may have the potential to benefit lifespan cognitive functioning by contributing to the cognitive reserve, a process proposed to reflect accumulated experience, cognitive skills and neural networks that enhance an individual's ability to cope with brain changes and protect against aging-related decline in cognitive performance (Stern 2009).

The benefits of breastfeeding on cognitive ability have been attributed to at least two factors. First, breastfeeding may benefit the infant's cognitive development through the maternal relationship, by supporting sensitive interactions with the parents and improving the infant's self-regulation capacities. Breastfeeding mothers have been found to display enhanced sensitivity during early infancy which may promote secure attachment (Britton et al. 2006), and skin-to-skin contact with the mother has been found to benefit self-regulation in preterm 
(Feldman et al. 2002) and term (Goldstein, Ferber \& Makhoul 2004) infants. Therefore, it has been suggested that association between breastfeeding and cognitive ability is susceptible to confounding by parental intelligence, home stimulation, and socioeconomic status (see review by Walfisch et al, 2013), and it has even been suggested that the advantage from breastfeeding is entirely due to parenting behaviors supportive of cognitive development (Gibbs \& Forste, 2014).

Second, breastfeeding can be beneficial due to nutritional causes. Breast milk contains longchained polyunsaturated fatty acids that are essential for neural development (Crawford 1993), which have been found to be more highly concentrated in the cerebral cortex of breastfed infants (Farquharson et al. 1992). Furthermore, genetic variants related to fatty acid metabolism have been found to moderate the association between breastfeeding and cognitive ability (Caspi et al. 2007), however this association was not replicated in another study (Martin et al. 2011).

Breastfeeding could also potentially exert benefits via the gut microbiome. There is evidence from animal studies that the gut microbiome can influence behavior and cognition (see review (Cryan \& Dinan 2012)). In humans breastfeeding alters the infant's microbiome, as human milk oligosaccharides (HMOs) function as prebiotics for beneficial bacteria (Huda et al. 2014; Ewaschuck et al. 2008; Fukuda et al. 2011). Also, in animal models milk oligosaccharides containing sialic acid have been found to have a microbiome-dependent role in promoting physical growth and to impact liver, muscle and brain metabolism (Charbonneau et al. 2016), and HMOs have a higher sialic acid content than those in bovine milk-based infant formulas (Wang et al. 2001). To our knowledge, however, thus far no studies exist that would have investigated whether these mechanisms impact human cognitive development. 
While our study is not able to address these mechanisms and potential confounding directly, it is notable that unlike in most populations (e.g. Mortensen et al. 2002; Richards et al. 2002), in our cohort breastfeeding was more prevalent in manual working families. This suggests that at least in our cohort the association of breastfeeding and cognitive ability is less likely to be only due to mothers from higher socioeconomic status families being more likely to have higher IQ's and being able to provide a higher quality home environment for their children.

Strengths of this study include measurement of cognitive ability at age 20.2 years and in a retest at age 67.9 years with the same test battery in a well-characterized lifespan longitudinal cohort of men. Further, unlike in many of the previous cohort studies, our data allowed adjusting for maternal and paternal occupational status, as proxies of parental intelligence. Limitations include sample attrition over five decades and subsequent selection bias affecting our results, and studying Finnish men only. While it is known that the predominant alternative to breastfeeding in this cohort was cow's milk, this study is not able to account for any differences in those not breastfed in our study population and those in the other previous studies (Gale \& Martyn, 1996; Mortensen et al. 2002; Richards et al. 2002; Victora et al. 2015) due time and place -related differences in breastfeeding alternatives and practices. We also were not able to account for potential health differences between mothers of the men who were breastfed and those who were not, and do not have data on reasons for not breastfeeding or potential confounding of breastfeeding duration due to factors such as maternal employment. Yet, one month payless obligatory maternity leave was introduced in Finland already in 1917. The pediatric and health center practice of the time was to encourage breastfeeding of mothers of all social classes, with very few exceptions, the most common of these being maternal lung disease. Even though our study was able to account for many important covariates, we were not able to account for a number of other potential factors that are associated with lifespan cognitive ability, such as lifestyle factors including smoking, 
alcohol, diet and physical activity, personality traits, stressful life events or sociobiological factors, such as food security; though in our sample breastfeeding was not related to physical growth up to 24 months indicating that breastfeeding was not related to early living conditions. Our sample, however, does not vary in place of residence in either childhood or in old age since we know that the participants were born in Helsinki, have data on early childhood physical growth measured at child welfare clinics located in the Helsinki area, and we invited men to the cognitive ability re-test if they lived within $200 \mathrm{~km}$ radius from Helsinki. While we are not aware of studies showing that these are related to breastfeeding, a possibility remains that some other factor explains our findings and hence residual confounding cannot be entirely ruled out. As the cohort was born in 1930s and 1940s, generalizations to cohorts born more recently cannot be made; this is, however, an unavoidable limitation that relates to studying the long-term effects of breastfeeding on cognitive aging in today's elderly. Generalizations cannot either be made to cohorts that differ from ours in sample characteristics.

In sum, we found that being ever breastfed and being breastfed for a longer duration were associated with better cognitive ability at 20.2 and 67.9 years, and that a longer duration of breastfeeding was associated with an increase in verbal reasoning over five decades in Finnish men. Consistent with earlier studies in British, Danish and Brazilian men and women (Mortensen et al. 2002; Victora et al. 2015; Richards et al. 2002) which have demonstrated that breastfeeding carries neurodevelopmental advantages up till middle adulthood, our study suggests that these benefits persist into old age and may lay grounds for lifelong improvement in verbal ability.

\section{Acknowledgements}


Financial support: This work was supported by The Academy of Finland (grant numbers 1284859, 269925, 12848591); the Finnish Diabetes Research society; Folkhälsan Research Foundation; Liv och Hälsa Foundation; Novo Nordisk Foundation; Finska Läkaresällskapet;

Signe and Ane Gyllenberg Foundation; University of Helsinki (grant number 60629); Ministry of Education; Ahokas Foundation; Emil Aaltonen Foundation; Juho Vainio Foundation; and Wellcome Trust.

The funding sources were not involved in study design, data collection, analysis, or interpretation, in writing the report, or decision to submit it for publication.

Declaration of interest: None of the authors have conflicts of interest to report.

\section{References}

Barker DJ, Osmond C, Forsén TJ, Kajantie E, Eriksson JG (2005). Trajectories of growth among children who have coronary events as adults. The New England Journal of Medicine 353, 1802-1809.

Britton JR, Britton HL, Gronwaldt V (2006). Breastfeeding, sensitivity, and attachment. Pediatrics 118, e1436-43.

Caspi A, Williams B, Kim-Cohen J, Craig IW, Milne BJ, Poulton R, Schalkwyk LC, Taylor A, Werts H, Moffitt TE (2007). Moderation of breastfeeding effects on the IQ by genetic variation in fatty acid metabolism. Proceedings of the National Academy of Sciences of the United States of America 104, 18860-18865.

Charbonneau MR, O’Donnell D, Blanton LV, Totten SM, Davis JCC, Barratt MJ, Cheng J, Guruge J, Talcott M, Bain JR, Muehlbauer MJ, Ilkayeva O, wu C, Struckmeyer T, Barlie D, Mangani C, Jorgensen J, Fan Y, Maieta K, Dewey KG, Ashom 
P, Newgard CB, Lebrilla C, Mills DA, Gordon JI (2016). Sialylated milk oligosaccharides promote microbiota-dependent growth in models of infant undernutrition. Cell 164, 859-871.

Crawford MA (1993). The role of essential fatty acids in neural development: implications for perinatal nutrition. The American Journal of Clinical Nutritrion 57, 7035-95.

Cryan JF, Dinan T (2012). Mind-altering microorganisms: the impact of the gut microbiota on brain and behaviour. Nature Reviews Neuroscience 13, 701-712.

Eriksson JG, Osmond C, Kajantie E, Forsén TJ, Barker DJ (2006). Patterns of growth among children who later develop type 2 diabetes or its risk factors. Diabetologia 49, 28532858.

Ewaschuck JB, Diaz H, Meddings L, Diederichs B, Dmytrash A, Backer J, Looijer-van Langen M, Madsen KL (2008). Secreted bioactive factors from Bifidobacterium infantis enhance epithelial cell barrier function. American Journal of Physiology Gastrointestinal and Liver Physiology 295, G1025-G1034.

Farquharson J, Cockburn F, Patrick WA, Jamieson EC, Logan RW (1992). Infant cerebral cortex phospholipid fatty-acid composition and diet. Lancet 340, 810-13.

Feldman R, Weller A, Sirota L, Eidelman A (2002). Skin-to-skin contact (kangaroo care) promotes self-regulation in premature infants: sleep-wake cyclicity, arousal modulation, and sustained exploration. Developmental Psychology 38, 194-207.

Fukuda S, Toh H, Hase K, Oshima K, Nakanishi Y, Yoshimura K, Tobe T, Clarke JM, Topping DL, Suzuki T, Taylor TD, Itoh K, Kikuchi J, Morita H, Hattori M, Ohno H (2011). Bifidobacteria can protect from enteropathogenic infection through production of acetate. Nature 469, 543-547. 
Gale CR, Martyn CN (1996). Breastfeeding, dummy use, and adult intelligence. Lancet 347, $1072-75$

Gibbs, BG \& Forste, R (2014). Breastfeeding, parenting, and early cognitive development. The Journal of Pediatrics 164:487-93.

Goldstein Ferber S, Makhoul IR (2004). The effect of skin-to-skin contact (Kangaroo Care) shortly after birth on the neurobehavioral responses of the term newborn: a randomized, controlled trial. Pediatrics 113, 858-865.

Habib R, Nyberg L, Nilsson LG (2007). Cognitive and non-cognitive factors contributing to the longitudinal identification of successful older adults in the Betula study. Aging, Neuropsychology and Cognition 14, 257-274.

Horta BL, Victora CG (2013). Long-term effects of breastfeeding: a systematic review. World Health Organization: Geneva.

Huda MN, Lewis Z, Kalanetra KM, Rashid M, Ahmad SM, Raqib R, Qadri F, Underwood Ma, Mills DA, Stephensen CB (2014). Stool microbiota and vaccine responses of infants. Pediatrics 134, e362-e372.

Kajantie E, Barker DJP, Osmond C, Forsén T, Eriksson JG (2008). Growth before 2 years of age and serum lipids 60 years later: The Helsinki Birth Cohort Study. International Journal of Epidemiology 37, 280-289.

Kajantie E, Raikkonen K, Henriksson M, Leskinen JT, Forsén T, Heinonen K, Pesonen AK, Osmond C, Barker DJ, Eriksson JG (2012). Stroke is predicted by low visuospatial in relation to other intellectual abilities and coronary heart disease by low general intelligence. PLoS One 7, e46841. 
Kramer MS, Aboud F, Mironova E, Vanilovich I, Platt RW, Matush L, Igumnov S, Fombonne E, Bogdanovich N, Ducruet T, Collet JP, Chalmers B, Hodnett E, Davidovsky S, Skugarevsky O, Trofimovich O, Kozlova L, Shapiro S, Promotion of Breastfeeding Intervention Trial (PROBIT) Study Group (2008). Breastfeeding and child cognitive development: new evidence from a large randomized trial. Archives of General Psychiatry 65, 578-584.

Martin NW, Benyamin B, Hansell NK, Montgomery GW, Martin NG, Wright MJ, Bates TC (2011). Cognitive function in adolescence: testing for interactions between breast-feeding and FADS2 polymorphisms. Journal of the American Academy of Child and Adolescent Psychiatry 50, 55-62.

Mortensen EL, Michaelsen KF, Sanders SA Reinisch JM (2002). The association between duration of breastfeeding and adult intelligence. JAMA 287, 2365-2946.

Osmond C, Kajantie E, Forsén TJ, Eriksson JG, Barker DJ (2007). Infant growth and stroke in adult life. The Helsinki Birth Cohort Study. Stroke 38, 264-270.

Park DC, Lautenchlager G, Hedden T, Davidson NS, Smith AD, Smith PK (2002). Models of visuospatial and verbal memory across the adult life span. Psychology and Aging 17, 299-320.

Patel R, Oken E, Bogdanovich N, Matush L, Sevkovskaya Z, Chalmers B, Hodnett ED, Vilchuck K, Kramer MS, Martin RM (2014). Cohort profile: The promotion of breastfeeding intervention trial (PROBIT). International Journal of Epidemiology 43, 679690. 
Pesonen A-K, Eriksson JG, Heinonen K, Kajantie E, Tuovinen S, Alastalo H,

Henriksson M, Leskinen J, Osmond C, Barker DJ, Raikkonen K (2013). Cognitive ability and decline after early life stress exposure. Neurobiology of Aging 34, 1674-1679.

Raikkonen K, Forsén T, Henriksson M, Kajantie E, Heinonen K, Pesonen AK, Leskinen JT, Laaksonen I, Osmond C, Barker DJ, Eriksson JG (2009). Growth trajectories and intellectual abilities in young adulthood: the Helsinki Birth Cohort Study. American Journal of Epidemiology 170, 447-455.

Raikkonen K, Lahti M, Heinonen K, Pesonen A-K, Wahlbeck K, Kajantie E, Osmond C, Barker DJP, Eriksson JG (2011). Risk of severe mental disorders in adults separated temporarily from their parents in childhood: The Helsinki birth cohort study. Journal of Psychiatric Research 45: 332-338.

Raikkonen K, Kajantie E, Pesonen AK, Heinonen K, Alastalo H, Leskinen JT, Nyman K, Henriksson M, Lahti J, Lahti M, Pyhälä R, Tuovinen S, Osmond C, Barker DJ, Eriksson JG (2013). Early life origins cognitive decline: findings in elderly men in the Helsinki birth cohort study. PLoS One 8, e54707.

Rantalainen V, Lahti J, Henriksson M, Kajantie E, Tienari P, Eriksson JG, Raikkonen K (2016). APOE and aging-related cognitive change in a longitudinal cohort of men. Neurobiology of Aging 44, 151-158.

Raven J (2000). The Raven's progressive matrices: Change and stability over culture and time. Cognitive Psychology 41, 1-48.

Richards M, Hardy R, Wadsworth MEJ (2002). Long-term effects of breast-feeding in a national birth cohort: educational attainment and midlife cognitive function. Public Health Nutrition 5, 631-635. 
Stern Y (2009). Cognitive reserve. Neuropsychologia 47, 2015-2028.

\section{Tiihonen J, Haukka J, Henriksson M, Cannon M, Kieseppä T, Laaksonen I, Sinivuo J,}

Lönnqvist J (2005). Premorbid intellectual functioning in bipolar disorder and schizophrenia: results from a cohort study of male conscripts. The American Journal of Psychiatry 162, 1904-1910.

Van Dijk KRA, Van Gerven PWM, Van Boxtel MPJ, Van der Elst W, Jones J (2008).

No protective effects of education during normal cognitive aging: results from the 6-year follow-up of the Maastricht Aging Study. Psychology and Aging 23, 119-130.

Victora CG, Horta BL, de Mola CL, Quevedo L, Pinheiro RT, Gigante DP, Gonçalves H, Barros F (2015). Association between breastfeeding and intelligence, educational attainment, and income at 30 years of age: a prospective birth cohort study from Brazil. Lancet Global Health 3, e199-205.

Walfisch A, Sermer C, Cressman A, Koren G (2013). Breast milk and cognitive development - the role of confounders: a systematic review. BMJ Open 3, e003259.

Wang B, Brand-Miller J, McVeagh P, Petosz P (2001). Concentration and distribution of sialic acid in human milk and infant formulas. The American Journal of Clinical Nutrition 74, $510-515$.

Wigg NR, Tong S, McMichael AJ, Baghurst PA, Vimpani G, Roberts R (1998). Does breastfeeding at six months predict cognitive development? Australian and New Zealand Journal of Public Health 22, 232-6. 


\section{Figure captions}

Figure 1. Cognitive ability total (Panel A), and verbal (B), arithmetic (C) and visuospatial (D) subtest scores at 67.9 years according to duration of breastfeeding (never, up to 3,3 to 6 , or 6 or more months). Abbreviation: $d=$ Cohen's $d$ (effect size) calculated as the difference between means divided by the pooled standard deviation weighted by sample size. $P$-values correspond to linear trends adjusted for age at cognitive ability testing and father's and mother's occupational status in childhood. Error bars represent standard errors. Numbers refer to Cohen's d (effect size) for each duration of breastfeeding compared to those never breastfed. 
Figure 2. Change in cognitive ability verbal subtest score between 20.2 and 67.9 years in those never breastfed and those breastfed for up to 3, 3 to 6 and 6 or more months.

Abbreviation: $\mathrm{d}=$ Cohen's $\mathrm{d}$ (effect size) calculated as the difference between means divided by the pooled standard deviation weighted by sample size. $P$-value corresponds to breastfeeding $\mathrm{x}$ time interaction adjusted for father's and mother's occupational status in childhood. Error bars represent standard errors. Numbers refer to Cohen's d (effect size) for each duration of breastfeeding compared to those never breastfed. 
Table 1. Sample characteristics according to history of breastfeeding.

\begin{tabular}{|c|c|c|c|}
\hline \multirow[b]{2}{*}{ Characteristic } & \multicolumn{2}{|c|}{ Breastfed $^{\mathrm{a}}$} & \multirow{2}{*}{$\begin{array}{c}\text { Group } \\
\text { difference }^{\mathrm{b}} \\
p\end{array}$} \\
\hline & No (158) & Yes (773) & \\
\hline \multicolumn{4}{|l|}{ At birth: } \\
\hline Mother's age at delivery $(\text { years })^{\mathrm{c}}$ & $28.3(5.5)$ & $28.5(5.5)$ & .747 \\
\hline Parity & & & .115 \\
\hline Primiparous & $67(42.4 \%)$ & $381(49.3 \%)$ & \\
\hline Multiparous & $91(57.6 \%)$ & $392(50.7 \%)$ & \\
\hline Father's occupational status & & & .021 \\
\hline Senior clerical & $42(26.6 \%)$ & $158(20.4 \%)$ & \\
\hline Junior clerical & $45(28.5 \%)$ & $176(22.8 \%)$ & \\
\hline Manual worker & $71(44.9 \%)$ & $423(54.7 \%)$ & \\
\hline Missing data & $0(0 \%)$ & $16(2.1 \%)$ & \\
\hline Mother's occupational status & & & .084 \\
\hline Senior clerical & $9(5.7 \%)$ & $22(2.8 \%)$ & \\
\hline Junior clerical & $51(32.2 \%)$ & $284(36.7 \%)$ & \\
\hline Manual worker & $72(45.6 \%)$ & $377(48.8 \%)$ & \\
\hline Missing data & $26(16.5 \%)$ & $90(11.6 \%)$ & \\
\hline Length of gestation (days) ${ }^{\mathrm{d}}$ & $279.8(10.5)$ & $278.0(13.1)$ & .108 \\
\hline Weight $(g)$ & $3524.2(436.5)$ & $3473.9(481.8)$ & .225 \\
\hline Length $(\mathrm{cm})^{\mathrm{e}}$ & $50.8(1.7)$ & $50.7(2.0)$ & .284 \\
\hline Ponderal index $\left(\mathrm{kg} / \mathrm{m}^{3}\right)^{\mathrm{f}}$ & $26.7(2.1)$ & $26.6(2.3)$ & .584 \\
\hline \multicolumn{4}{|l|}{ At 0.5 years: } \\
\hline Weight (kg) & $7.9(0.9)$ & $7.9(0.9)$ & .788 \\
\hline Height $(\mathrm{cm})^{\mathrm{g}}$ & $67.8(2.0)$ & $67.9(2.3)$ & .546 \\
\hline Body mass index $\left(\mathrm{kg} / \mathrm{m}^{2}\right)^{\mathrm{h}}$ & $17.3(1.5)$ & $17.1(1.4)$ & .149 \\
\hline \multicolumn{4}{|l|}{ At 2 years: } \\
\hline Weight (kg) & $12.4(1.1)$ & $12.4(1.3)$ & .843 \\
\hline Height $(\mathrm{cm})^{\mathrm{i}}$ & $86.5(3.0)$ & $86.9(3.1)$ & .215 \\
\hline Body mass index $\left(\mathrm{kg} / \mathrm{m}^{2}\right)^{\mathrm{j}}$ & $16.8(1.1)$ & $16.6(1.2)$ & .083 \\
\hline \multicolumn{4}{|l|}{ At 20.2 years: } \\
\hline Age at cognitive testing (years) & $20.2(1.6)$ & $20.2(1.5)$ & .974 \\
\hline \multicolumn{4}{|l|}{ Cognitive ability score ${ }^{\mathrm{k}}$} \\
\hline Total score & $98.1(15.6)$ & $100.4(14.9)$ & .076 \\
\hline Verbal subtest & $98.7(15.4)$ & $100.3(14.9)$ & .238 \\
\hline Arithmetic subtest & $98.4(15.7)$ & $100.3(14.9)$ & .154 \\
\hline Visuospatial subtest & $97.3(15.1)$ & $100.5(14.9)$ & .014 \\
\hline
\end{tabular}




\section{At 67.9 years:}

Age at cognitive testing (years)

Cognitive ability score

Total score

$100.5(15.2)$

.034

Verbal subtest

Arithmetic subtest

Visuospatial subtest

Highest own achieved level of education

Upper tertiary

Lower tertiary

Basic or less

Marital status

$$
2(1.3 \%)
$$

Married / Widowed

Figures are mean (standard deviation) or number of participants (percentage).

a Of the analytic sample of 931 men, $773(83.0 \%)$ were breastfed, and of those 249 (26.7\%), 211 $(22.7 \%)$, and $312(33.5 \%)$ were breastfed for up to 3,3 to 6 , or 6 or more months, respectively.

b $P$-values correspond to group comparisons with chi-square test for parity, father's occupational status, mother's occupational status. highest own achieved level of education and marital status, ANOVA for others.

c One man had missing data in mother's age at delivery.

d 62 men had missing data in length of gestation.

e 11 men had missing data in birth length.

f 11 men had missing data in ponderal index at birth.

$\mathrm{g}$ One man had missing data in height at 0.5 years.

$\mathrm{h}$ One man had missing data in body mass index at 0.5 years.

i One man had missing data in height at 2 years.

j One man had missing data in body mass index at 2 years.

$\mathrm{k}$ Two men had missing data in the total and arithmetic subtest scores at 20.2 years. 
Table 2. Associations between breastfeeding status and cognitive ability at 20.2 and 67.9 years.

Being ever breastfed: Not

Total score

Verbal subtest score

Arithmetic subtest score Visuospatial subtest score

breastfed vs yes

\begin{tabular}{llllllllllll}
\hline $\mathrm{B}$ & $95 \% \mathrm{CI}$ & $p^{\mathrm{a}}$ & $\mathrm{B}$ & $95 \% \mathrm{CI}$ & $p^{\mathrm{a}}$ & $\mathrm{B}$ & $95 \% \mathrm{CI}$ & $p^{\mathrm{a}}$ & $\mathrm{B}$ & $95 \% \mathrm{CI}$ & $p^{\mathrm{a}}$
\end{tabular}

\section{At 20.2 years}

Unadjusted

2.31

$-0.27,4.88$

079

1.45

Model $1^{\mathrm{c}}$

3.23

$0.87,5.58$

3.00

$0.63,5.37$

$\begin{array}{lll}.079 & 1.45 \\ .007 & 2.39 & 0 .\end{array}$

$-1.12,4.02$

$269+1.80$

Model $2^{\mathrm{d}}$

\section{$\underline{\text { At } 67.9 \text { years }}$}

\begin{tabular}{|c|c|c|c|c|c|c|c|c|c|c|c|c|}
\hline Unadjusted & 2.78 & $0.21,5.34$ & .034 & 2.64 & $0.07,5.20$ & .044 & 2.37 & $-0.19,4.94$ & .070 & 2.37 & $-0.20,4.94$ & .070 \\
\hline Model $3^{\mathrm{e}}$ & 3.27 & $0.80,5.74$ & .010 & 3.30 & $0.79,5.80$ & .010 & 2.67 & $0.17,5.16$ & .036 & 2.77 & $0.26,5.29$ & .031 \\
\hline Model $4^{\mathrm{f}}$ & 2.95 & $0.45,5.44$ & .021 & 2.84 & $0.32,5.37$ & .027 & 2.52 & $0.05,5.03$ & .050 & 2.52 & $-0.03,5.07$ & .052 \\
\hline Model $5^{\mathrm{g}}$ & 3.39 & $1.22,5.57$ & .002 & 3.28 & $0.95,5.60$ & .006 & 2.97 & $0.76,5.18$ & .008 & 2.69 & $0.34,5.04$ & .025 \\
\hline Model $6^{\mathrm{h}}$ & 3.31 & $0.84,5.78$ & .009 & 3.31 & $0.80,5.81$ & .010 & 2.71 & $0.21,5.20$ & .034 & 2.84 & $0.32,5.36$ & .027 \\
\hline
\end{tabular}

Abbreviations: $\mathrm{B}=$ mean difference in cognitive ability scores between those breastfed and those never breastfed; $95 \%$ CI=95\% confidence interval.

a All cognitive ability scores are standardized to a normal distribution with mean 100 and standard deviation 15 .

b $P$-values correspond to tests of differences between those never breastfed and those breastfed. 
c Model 1 adjusted for age at cognitive ability testing and mother's and father's occupational status during childhood.

d Model 2 adjusted for age at cognitive ability testing, mother's and father's occupational status during childhood, mother's age at delivery, parity, gestational length, birth weight and gain in weight between birth and 6 months, and 6 months and 24 months.

e Model 3 adjusted for age at cognitive ability retest and mother's and father's occupational status during childhood.

f Model 4 adjusted for age at cognitive ability retest, mother's and father's occupational status during childhood, mother's age at delivery, parity, gestational length, birth weight and gain in weight between birth and 6 months, and 6 months and 24 months.

g Model 5 adjusted for age at cognitive ability retest, own highest attained lifetime education and marital status.

h Model 6 excluded men with diagnoses of stroke, coronary heart disease and any mental disorder, and used Model 3 covariates. 
Table 3. Associations between breastfeeding duration and cognitive ability at 20.2 and 67.9 years

\begin{tabular}{|c|c|c|c|c|c|c|c|c|c|c|c|c|}
\hline & \multicolumn{3}{|c|}{ Total score } & \multicolumn{3}{|c|}{ Verbal subtest score } & \multicolumn{3}{|c|}{ Arithmetic subtest score } & \multicolumn{3}{|c|}{ Visuospatial subtest score } \\
\hline $\begin{array}{l}\text { Breastfeeding } \\
\text { duration: never } \\
\text { breastfed vs }\end{array}$ & MD & $95 \% \mathrm{CI}$ & $p^{\mathrm{a}}$ & MD & $95 \% \mathrm{CI}$ & $p^{\mathrm{a}}$ & MD & $95 \% \mathrm{CI}$ & $p^{\mathrm{a}}$ & MD & $95 \% \mathrm{CI}$ & $p^{\mathrm{a}}$ \\
\hline
\end{tabular}

\section{At 20.2 years}

Unadjusted

$\begin{array}{rrrrrrrrrrrrr}\text { up to } 3 \text { months } & 1.32 & -1.68,4.32 & .389 & 1.41 & -1.59,4.40 & .358 & 0.61 & -2.39,3.61 & .690 & 1.90 & -1.09,4.88 & .213 \\ \text { 3 to 6 months } & 2.91 & -0.20,6.01 & .066 & 1.47 & -1.63,4.57 & .353 & 2.59 & -0.51,5.70 & .102 & 4.01 & 0.93,7.10 & .011 \\ \text { than 6 months } & 2.69 & -0.19,5.57 & .067 & 1.51 & -1.37,4.39 & .303 & 2.18 & -0.70,5.06 & .137 & 3.87 & 1.01,6.74 & .008 \\ \text { linear trend } & 0.89 & 0.01,1.76 & .048 & 0.38 & -0.50,1.26 & .393 & 0.08 & -0.07,1.68 & .073 & 1.27 & 0.39,2.14 & .005\end{array}$

Model $1^{\mathrm{c}}$

$\begin{array}{rrrrrrrrrrrrr}\text { up to } 3 \text { months } & 2.15 & -0.59,4.88 & .270 & 2.24 & -0.52,5.00 & .111 & 1.33 & -1.48,4.14 & .353 & 2.38 & -1.15,4.88 & .225 \\ \text { 3 to 6 months } & 3.15 & 0.32,5.98 & .029 & 1.78 & -1.08,4.64 & .221 & 2.78 & -0.13,5.69 & .061 & 4.07 & 1.13,7.01 & .100 \\ \text { than 6 months } & 3.15 & 0.32,5.98 & .002 & 2.95 & 0.29,5.60 & .030 & 3.38 & 0.68,6.09 & .014 & 4.89 & 2.16,7.63 & .007 \\ \text { linear trend } & 1.28 & 0.47,2.08 & .002 & 0.77 & -0.04,1.58 & .063 & 1.12 & 0.30,1.94 & .008 & 1.55 & 0.72,2.38 & <.001\end{array}$

Model $2^{\mathrm{d}}$

$\begin{array}{rrrrrrrrrrrrr}\text { up to } 3 \text { months } & 1.85 & -0.90,4.60 & .186 & 1.87 & -0.91,4.64 & .188 & 1.08 & -1.74,3.91 & .452 & 2.25 & -0.62,5.11 & .124 \\ 3 \text { to } 6 \text { months } & 3.00 & 0.16,5.84 & .039 & 1.64 & -1.23,4.51 & .262 & 2.68 & -0.24,5.60 & .072 & 3.94 & 0.98,6.90 & .009 \\ \text { more than 6 months } & 3.92 & 1.27,6.57 & .004 & 2.65 & -0.03,5.33 & .053 & 3.24 & 0.52,5.97 & .020 & 4.78 & 2.02,7.54 & .001\end{array}$


$\begin{array}{lllllllllllll}\text { linear trend } & 1.24 & 0.43,2.04 & .003 & 0.71 & -0.10 .1 .53 & .086 & 1.11 & 0.28,1.94 & .009 & 1.53 & 0.68,2.37 & <.001\end{array}$

\section{At 67.9 years}

Unadjusted

$\begin{array}{rrrrrrrrrrrrr}\text { up to 3 months } & 0.98 & -2.01,3.96 & .521 & 1.07 & -1.91,4.06 & .481 & 0.52 & -2.46,3.51 & .731 & 1.53 & -1.46,4.52 & .316 \\ \text { 3 to 6 months } & 3.62 & 0.53,6.70 & .022 & 3.09 & 0.01,6.18 & .050 & 3.56 & 0.48,6.65 & .024 & 2.34 & -0.75,5.44 & .138 \\ \text { more than 6 months } & 3.64 & 0.78,6.51 & .013 & 3.63 & 0.76,6.29 & .013 & 2.99 & 0.1235 .85 & .041 & 3.06 & 0.19,5.93 & .037 \\ \text { linear trend } & 1.31 & 0.44,2.19 & .003 & 1.27 & 0.39,2.14 & .005 & 1.15 & 0.28,2.03 & .010 & 0.95 & 0.08,1.83 & .033\end{array}$

Model $3^{\mathrm{e}}$

$\begin{array}{rrrrrrrrrrrrr}\text { up to } 3 \text { months } & 1.63 & -1.22,4.51 & .261 & 1.73 & -1.17,4.63 & .243 & 1.00 & -1.89,3.90 & .497 & 2.18 & -0.74,5.11 & .144 \\ 3 \text { to } 6 \text { months } & 3.30 & 0.33,6.28 & .030 & 3.16 & 0.15,6.18 & .040 & 3.14 & 0.13,6.14 & .041 & 2.06 & -0.98,5.10 & .184 \\ \text { than 6 months } & 4.57 & 1.81,7.33 & .001 & 4.70 & 1.91,7.49 & .001 & 3.69 & 0.90,6.47 & .010 & 3.74 & 0.92,6.56 & .009 \\ \text { linear trend } & 1.52 & 0.68,2.36 & <.001 & 1.54 & 0.68,2.36 & <.001 & 1.30 & 0.45,1.94 & .003 & 1.07 & 0.21,1.94 & .015\end{array}$

Model $4^{\mathrm{f}}$

$\begin{array}{rrrrrrrrrrrrr}\text { up to } 3 \text { months } & 1.32 & -1.56,4.20 & .368 & 1.34 & -1.58,4.26 & .367 & 0.76 & -2.15,3.67 & .608 & 2.00 & -0.95,4.96 & .183 \\ 3 \text { to } 6 \text { months } & 3.07 & 0.07,6.06 & .045 & 2.84 & -0.20,5.87 & .067 & 3.03 & 0.01,6.05 & .049 & 1.87 & -1.20,4.94 & .232 \\ \text { more than 6 months } & 4.22 & 1.43,7.00 & .003 & 4.13 & 1.31,6.95 & .004 & 3.60 & 0.80,6.41 & .012 & 3.40 & 0.55,6.25 & .019 \\ \text { linear trend } & 1.43 & 0.58,2.28 & .001 & 1.39 & 0.53,2.25 & .002 & 1.30 & 0.45,2.16 & .003 & 0.97 & 0.10,1.84 & .029\end{array}$

Model $5^{\mathrm{g}}$

$\begin{array}{lllllllllllll}\text { up to } 3 \text { months } & 2.04 & -0.49,4.57 & .114 & 1.97 & -0.73,4.67 & .153 & 1.57 & -1.00,4.14 & .230 & 2.22 & -0.52,4.96 & .112\end{array}$ 


$\begin{array}{rrrrrrrrrrrrrr}3 \text { to 6 months } & 3.70 & 1.08,6.33 & .006 & 3.35 & 0.54,6.15 & .019 & 3.68 & 1.02,6.35 & .007 & 2.22 & -0.63,5.06 & .126 \\ \text { more than 6 months } & 4.27 & 1.84,6.70 & .001 & 4.32 & 1.72,6.92 & .001 & 3.57 & 1.10,6.04 & .005 & 3.38 & 0.74,6.02 & .012 \\ \text { linear trend } & 1.37 & 0.62,2.11 & <.001 & 1.38 & 0.58 .2 .17 & .001 & 1.19 & 0.44,1.95 & .002 & 0.95 & 0.14,1.76 & .021 \\ \text { Model 6 } & & & & & & & & & & & & & \\ \text { up to 3 months } & 1.73 & -1.14,4.59 & .237 & 1.76 & -1.14,4.67 & .233 & 1.09 & -1.80,3.99 & .459 & 2.21 & -0.72,5.14 & .139 \\ \text { 3 to 6 months } & 3.37 & 0.39,6.35 & .027 & 3.16 & 0.14,6.17 & .040 & 3.22 & 0.21,6.23 & .036 & 2.17 & -0.87,5.22 & .162 \\ \text { more than 6 months } & 4.57 & 1.81,7.33 & .001 & 4.70 & 1.91,7.50 & .001 & 3.66 & 0.87,6.45 & .010 & 3.80 & 0.97,6.62 & .008 \\ \text { linear trend } & 1.51 & 0.67,2.35 & <.001 & 1.54 & 0.68,2.39 & <.001 & 1.28 & 0.43,2.13 & .003 & 1.10 & 0.23,1.96 & .013\end{array}$

a All cognitive ability scores are standardized to a normal distribution with mean 100 and standard deviation 15.

b $P$-values correspond to tests of differences between those never breastfed and those breastfed.

c Model 1 adjusted for age at cognitive ability testing and mother's and father's occupational status during childhood.

d Model 2 adjusted for age at cognitive ability testing, mother's and father's occupational status during childhood, mother's age at delivery, parity, gestational length, birth weight and gain in weight between birth and 6 months, and 6 months and 24 months.

e Model 3 adjusted for age at cognitive ability retest and mother's and father's occupational status during childhood.

f Model 4 adjusted for age at cognitive ability retest, father's and mother's occupational status during childhood, mother's age at delivery, parity, gestational length, birth weight and gain in weight between birth and 6 months, and 6 months and 24 months. 
g Model 5 adjusted for age at cognitive ability retest, own highest attained lifetime education and marital status.

h Model 6 excluded men with diagnoses of stroke, coronary heart disease or any mental disorder, and used Model 3 covariates. 


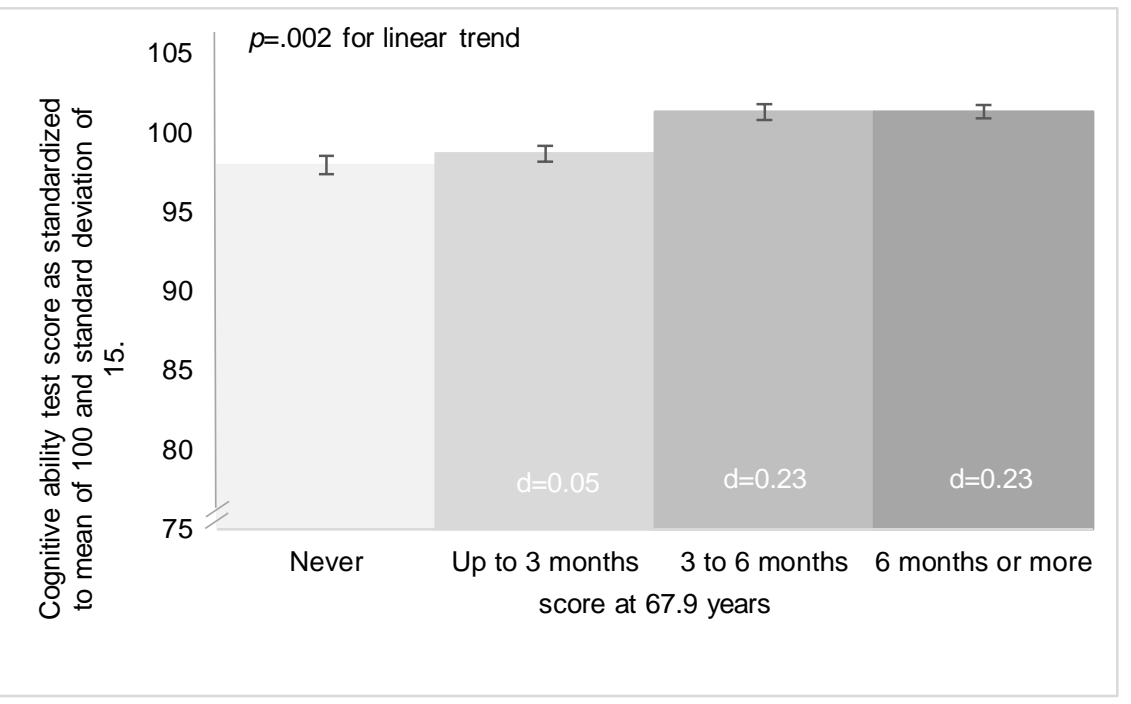

C

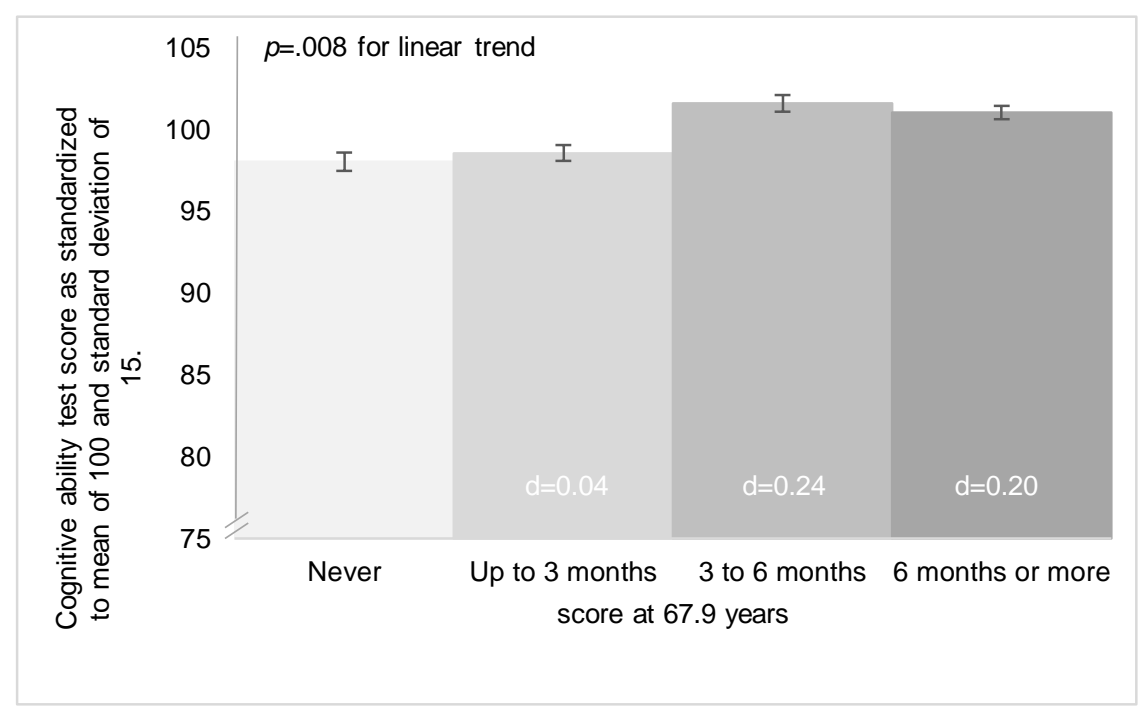

B

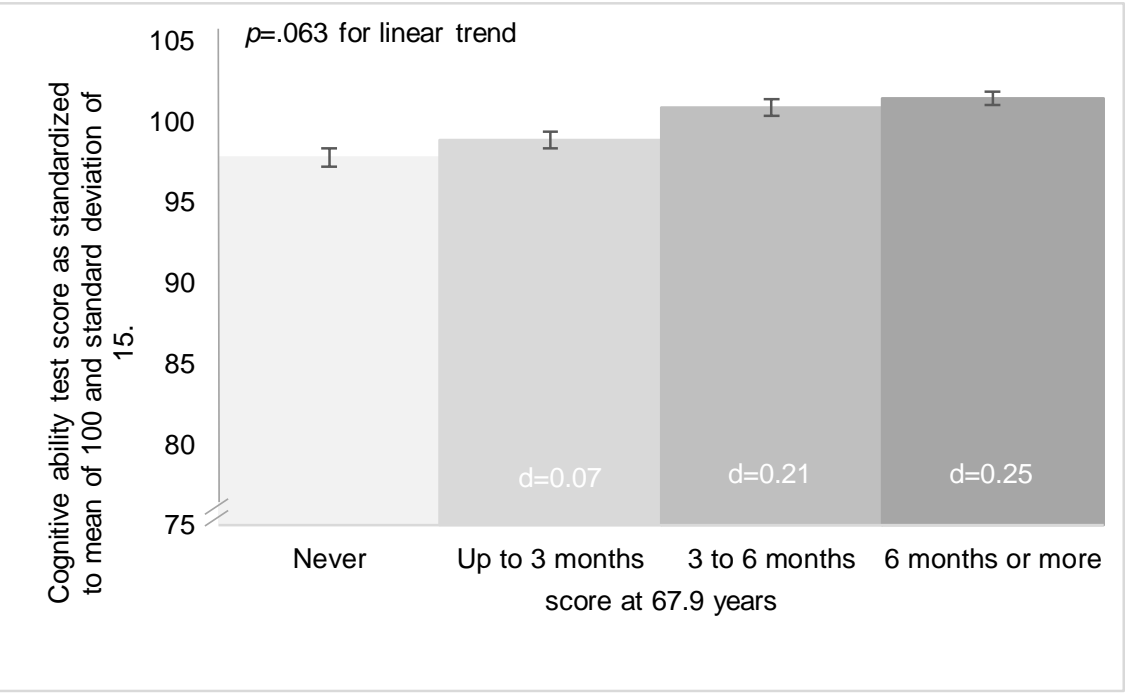

D

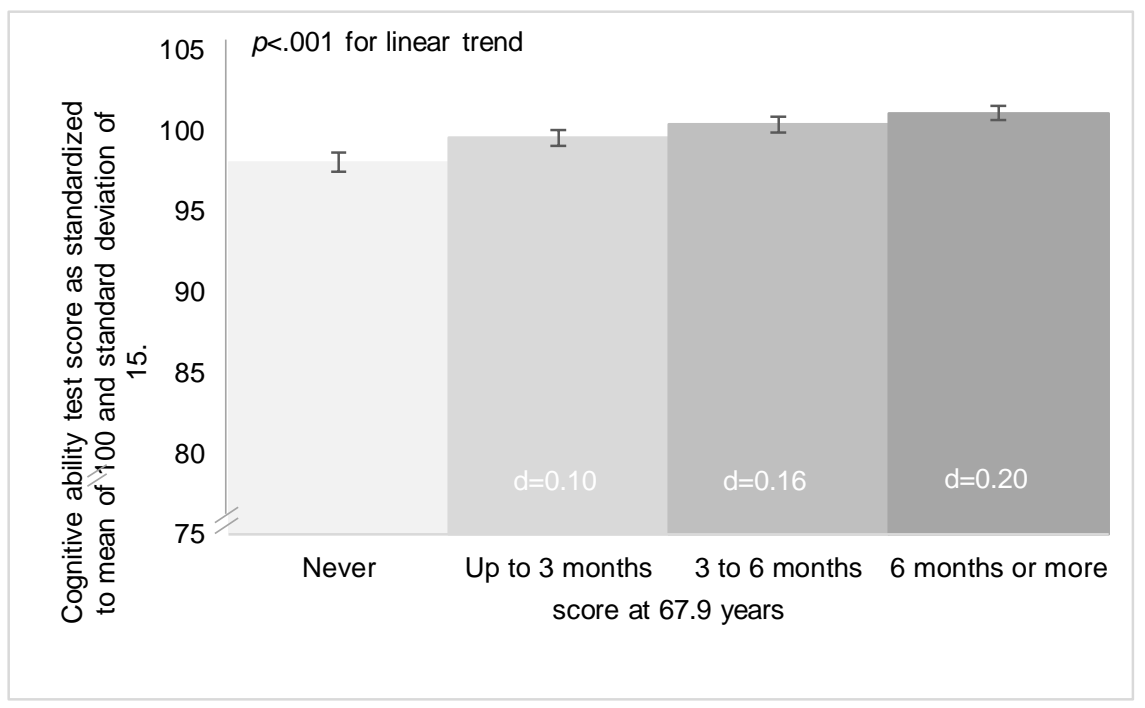



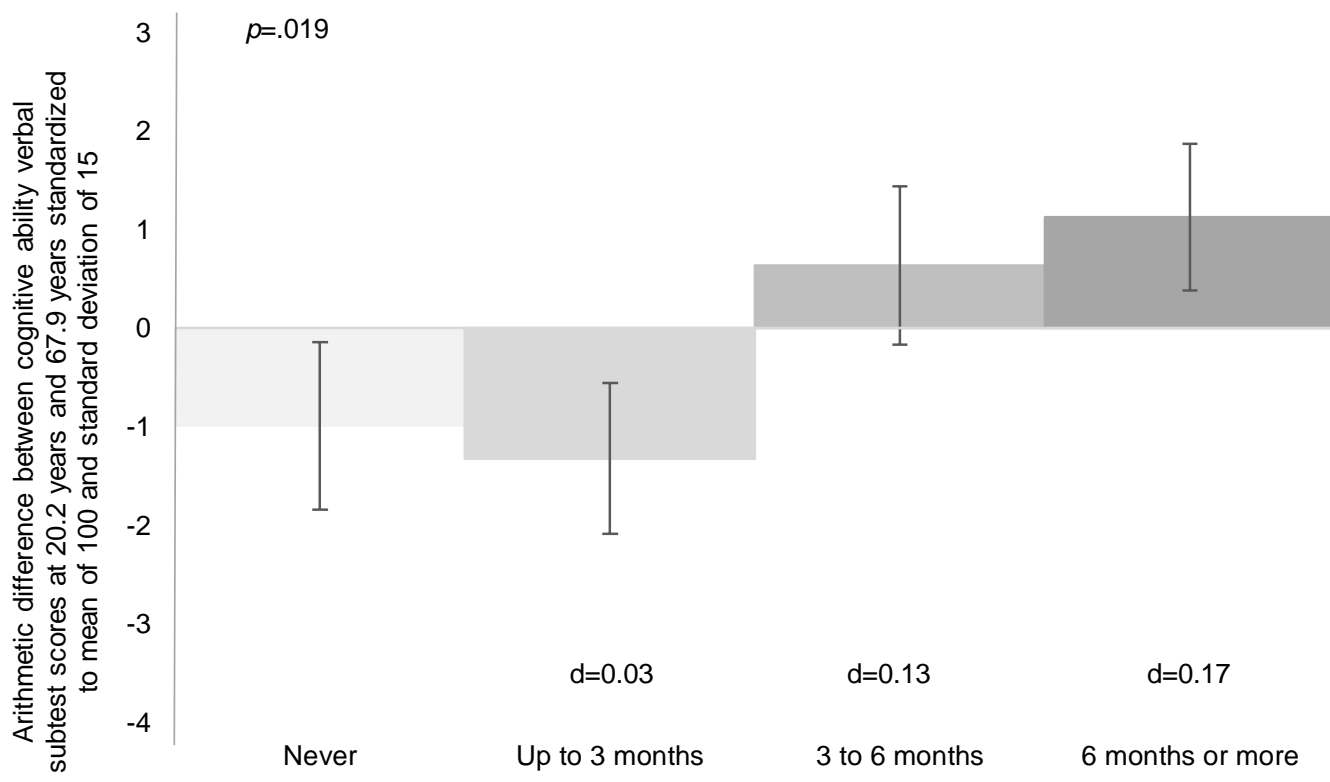

change score 


\begin{tabular}{|c|c|c|c|c|c|}
\hline \multicolumn{6}{|c|}{$\begin{array}{l}\text { Supplementary Table } 1 \text {. Characteristics of the cohort who had data on breastfeeding but did not have } \\
\text { data on cognitive ability in old age according to history of breastfeeding. }\end{array}$} \\
\hline \multirow[b]{2}{*}{ Characteristic } & \multicolumn{2}{|c|}{ Breastfed } & \multirow{2}{*}{$\begin{array}{c}\text { Group } \\
\text { difference } \\
p^{\mathrm{a}}\end{array}$} & \multicolumn{2}{|c|}{$\mathrm{N}$ breastfed } \\
\hline & No & Yes & & No & Yes \\
\hline \multicolumn{6}{|l|}{ At birth } \\
\hline Mother's age at delivery (years) & $28.10(5.36)$ & $28.23(5.45)$ & .592 & 606 & 3092 \\
\hline Parity & & & .770 & 606 & 3093 \\
\hline Primiparous & $297(49.0 \%)$ & $1536(49.7 \%)$ & & & \\
\hline Multiparous & $309(51.0 \%)$ & $1557(50.3 \%)$ & & & \\
\hline Father's occupational status & & & .003 & 606 & 3093 \\
\hline Senior clerical & $124(20.5 \%)$ & $462(14.9 \%)$ & & & \\
\hline Junior clerical & $136(22.4 \%)$ & $696(22.5 \%)$ & & & \\
\hline Manual worker & $329(54.3 \%)$ & $1871(60.5 \%)$ & & & \\
\hline Missing data & $17(2.8 \%)$ & $64(2.1 \%)$ & & & \\
\hline Mother's occupational status & & & .025 & 606 & 3093 \\
\hline Senior clerical & $34(5.6 \%)$ & $100(3.2 \%)$ & & & \\
\hline Junior clerical & $177(29.2 \%)$ & $985(31.8 \%)$ & & & \\
\hline Manual worker & $321(53.0 \%)$ & $1655(53.5 \%)$ & & & \\
\hline Missing data & $74(12.2 \%)$ & $353(11.4 \%)$ & & & \\
\hline Length of gestation (days) & $279.2(12.4)$ & $278.6(14.9)$ & .349 & 592 & 3037 \\
\hline Weight $(\mathrm{g})$ & $3466.2(486.7)$ & $3446.6(494.4)$ & .370 & 606 & 3093 \\
\hline Length $(\mathrm{cm})$ & $50.7(2.0)$ & $50.6(2.0)$ & .404 & 596 & 3058 \\
\hline Ponderal index $\left(\mathrm{kg} / \mathrm{m}^{3}\right)$ & $26.6(2.2)$ & $26.48(2.2)$ & .441 & 596 & 3058 \\
\hline \multicolumn{6}{|l|}{ At 0.5 years } \\
\hline Weight (kg) & $7.88(0.92)$ & $7.86(0.89)$ & .681 & 601 & 3079 \\
\hline Height $(\mathrm{cm})^{\mathrm{g}}$ & $67.64(2.28)$ & $67.69(2.33)$ & .578 & 598 & 3078 \\
\hline Body mass index $\left(\mathrm{kg} / \mathrm{m}^{2}\right)$ & $17.19(1.46)$ & $17.14(1.43)$ & .514 & 599 & 3077 \\
\hline \multicolumn{6}{|l|}{ At 2 years } \\
\hline Weight (kg) & $12.32(1.16)$ & $12.32(1.18)$ & .994 & 601 & 3082 \\
\hline Height $(\mathrm{cm})$ & $86.44(3.12)$ & $86.45(3.19)$ & .934 & 599 & 3079 \\
\hline Body mass index $\left(\mathrm{kg} / \mathrm{m}^{2}\right)$ & $16.64(1.25)$ & $16.64(1.22)$ & .995 & 600 & 3079 \\
\hline \multicolumn{6}{|l|}{ At 67.9 years } \\
\hline $\begin{array}{l}\text { Highest own achieved level of } \\
\text { education }\end{array}$ & & & .144 & 562 & 2942 \\
\hline Upper tertiary & $74(12.2 \%)$ & $309(10.0 \%)$ & & & \\
\hline Lower tertiary & $120(19.8 \%)$ & $571(18.5 \%)$ & & & \\
\hline Upper secondary & $137(22.6 \%)$ & $772(25.0 \%)$ & & & \\
\hline Basic or less & $231(38.1 \%)$ & $1290(41.7 \%)$ & & & \\
\hline Any mental disorder & & & .801 & 605 & 3079 \\
\hline No & $486(80.2 \%)$ & $2487(80.4 \%)$ & & & \\
\hline Yes & $119(19.6 \%)$ & $592(19.1 \%)$ & & & \\
\hline Marital status & & & .114 & 562 & 2942 \\
\hline Never married & $84(13.9 \%)$ & $347(11.2 \%)$ & & & \\
\hline Married/Widowed & $298(49.2 \%)$ & $1619(52.3 \%)$ & & & \\
\hline Divorced & $180(29.7 \%)$ & $976(31.6 \%)$ & & & \\
\hline
\end{tabular}

Figures are mean (standard deviation) or number of participants (percentage).

a $P$-values correspond to group comparisons with chi-square test for parity, father's occupational status, mother's occupational status and highest own achieved level of education, ANOVA for others. 
Supplementary Table 2. Father's and mother's occupational status.

Mother's occupation

\begin{tabular}{lcccc} 
Father's occupation & Upper clerical & Lower clerical & Manual worker & Missing \\
\hline Upper clerical & $21(67.7 \%)$ & $100(29.9 \%)$ & $36(8.0 \%)$ & $43(37.1 \%)$ \\
Lower clerical & $5(16.1 \%)$ & $109(32.5 \%)$ & $76(16.9 \%)$ & $31(26.7 \%)$ \\
Manual worker & $5(16.1 \%)$ & $122(36.4 \%)$ & $326(72.6 \%)$ & $41(35.3 \%)$ \\
Missing & $0(0 \%)$ & $4(1.2 \%)$ & $11(2.4 \%)$ & $1(0.9 \%)$ \\
\hline
\end{tabular}

Figures are number of participants (percentage). $\chi^{2}(9)=181.3, p<.001$ 